\title{
AC 2012-5133: INSTRUCTOR'S PERSPECTIVES OF TRANSFORMING A TRADITIONAL ENGINEERING ECONOMICS COURSE INTO A FULLY ONLINE DELIVERY
}

\section{Ms. Pil-Won On, University of Missouri, Columbia}

Pil-Won On is am Instructional Designer/E-learning Specialist at the College of Engineering, University of Missouri, Columbia. On holds an M.S. in instructional systems technology from Indiana University, Bloomington.

Dr. Luis Occena, University of Missouri, Columbia 


\section{Instructor's Perspectives of Transforming a Traditional Engineering Economics Course into a Fully Online Delivery}

\section{Background}

Promoting quality learning is one of the growing interests in engineering. More engineering professors have presented in educational publications and conventions to demonstrate their efforts to make better educational values available to their students. The interests and efforts for quality learning in academia have led higher-education administrators and professors to question how engineering is taught traditionally. ${ }^{2,3}$

Adapting emerging technologies into educational practices has been suggested as one of the ways to promote quality learning. E-learning becomes inevitably popular while more and more educational practitioners try to improve teaching and learning with technology. However, online education in engineering is not yet widespread throughout all engineering education disciplines. ${ }^{1}$ In addition, it is rarely found that educational research conducted in engineering deals with instructor's perspectives of promoting quality learning with use of technologies in teaching. ${ }^{4}$

One of the authors has been teaching Engineering Economics for more than a decade with some degree of technology adaptation in the course delivery. The use of a course management system (CMS) such as Blackboard ${ }^{\mathrm{TM}}$ which is centrally supported by an affiliated higher-education institution has been a major implementation of technology in teaching and learning. A course site in CMS was mainly used for storing and disseminating course content such as lecture notes and reading materials. A user's performance tracking record was occasionally used to check on certain student's current status, but employed in a basic level of application.

In order to expand the course offering to more prospective students, the instructor tried to convert the course into a fully-online version offering as an e-learning option. Even though the instructor was experienced with Blackboard ${ }^{\mathrm{TM}}$ for years, it was challenging to create an online course delivered fully online without appropriate instructional design and development support.

\section{Design and Development of Engineering Economics Online}

The instructor teamed up with an instructional designer to transform the course into a fullyonline delivery. During the transformation process, the instructor experienced a dramatic difference from receiving appropriate instructional design and development support. Table 1 summarizes the path of transformation reflected on the instructor's perspectives. It highlights 10 key features which demonstrate significant difference that the instructor perceived during the transformation. 


\begin{tabular}{|c|c|c|c|}
\hline & Key Features & $\begin{array}{c}\text { Before Receiving } \\
\text { Instructional Support }\end{array}$ & $\begin{array}{c}\text { After Working with } \\
\text { Instructional Designer }\end{array}$ \\
\hline 1 & Course layout & Unit based (6 units) & $\begin{array}{l}\text { Weekly topic based ( } 15 \text { main } \\
\text { concepts) }\end{array}$ \\
\hline 2 & Learning process & Instructor-led & Automated with mastery learning \\
\hline 3 & Course structure & $\begin{array}{l}\text { Collection of content (reading } \\
\text { materials, lecture notes, } \\
\text { assignments) }\end{array}$ & $\begin{array}{l}\text { Weekly learning modules framed } \\
\text { with topic-level learning objectives }\end{array}$ \\
\hline 4 & Alignment & Unsure & $\begin{array}{l}\text { Measurable learning objectives } \\
\text { aligned with desired learning } \\
\text { outcomes }\end{array}$ \\
\hline 5 & Content format & Text (pdf format) & $\begin{array}{l}\text { Visual aids (lecture recording, online } \\
\text { text, web resources, graphics) }\end{array}$ \\
\hline 6 & Practice & $\begin{array}{l}\text { Class lectures, and } \\
\text { assignments that were hand- } \\
\text { graded }\end{array}$ & $\begin{array}{l}\text { Reading quiz and practice questions } \\
\text { (assignment) in each week } \\
\text { (predetermined level of success, } \\
\text { unlimited attempts, prompt feedback) }\end{array}$ \\
\hline 7 & Assessment & $\begin{array}{l}\text { Online tests, assignment } \\
\text { submission with no evaluation } \\
\text { criteria }\end{array}$ & $\begin{array}{l}\text { Online tests only, auto-graded, } \\
\text { individualized question sets selected } \\
\text { from three difficulty levels (easy/ } \\
\text { intermediate/difficult) }\end{array}$ \\
\hline 8 & Monitoring & $\begin{array}{l}\text { Infrequent use of performance } \\
\text { tracking record }\end{array}$ & $\begin{array}{l}\text { Scheduled checkups and follow-ups } \\
\text { through Early Warning System }\end{array}$ \\
\hline 9 & Help session & Face-to-face office hours & $\begin{array}{l}\text { Virtual office through web } \\
\text { conferencing, weekly Q\&A forums }\end{array}$ \\
\hline 10 & Orientation & First day face-to-face lecture & $\begin{array}{l}\text { "Welcome! Start here" folder on the } \\
\text { homepage (including instructor's } \\
\text { greetings and introduction to the } \\
\text { course, course walk-through video, } \\
\text { introductory activity, syllabus quiz ) }\end{array}$ \\
\hline
\end{tabular}

Table 1. Path of Transformation: Before and After

The detail discussion of how the course was converted from a text-based, instructor-led, content repository to a systemic mastery learning format is following.

Key Feature 1 \& 2: Course Layout \& Learning Process

It is common that an engineering course curriculum is framed within major units based on main topics. However, it creates an inconsistent workflow so that students easily get confused with how they organize their learning. It is intuitive that people manage their everyday life weekly. As an online delivery requires students to be more autonomous and to lead their learning by themselves, the weekly-based framework enables them to stay on task in a timely manner. 


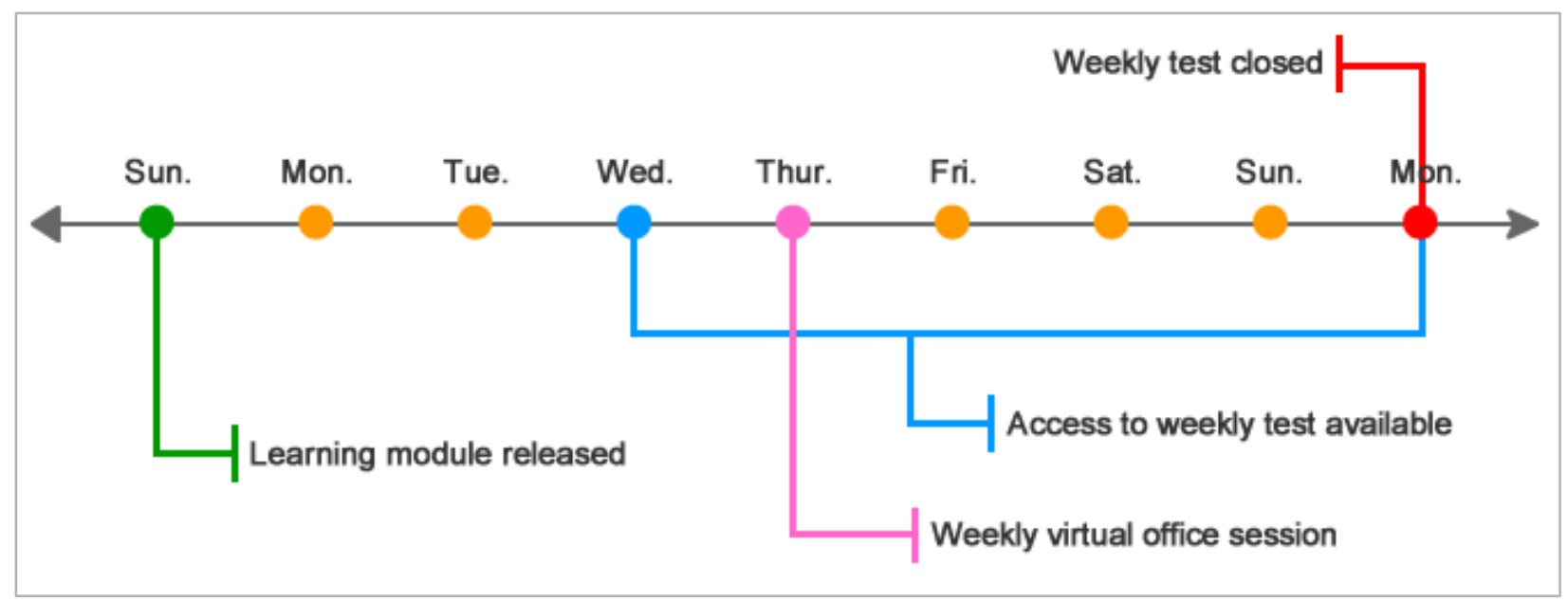

Figure 1. Automated Learning Process after Transformation

As shown in Figure 1, the learning process is automated in a week-based timeframe. The next learning module is released based on a submission of a weekly test or at midnight on Sunday. The learning activities such as a reading quiz and an assignment are designed to accomplish the desired mastery of learning.

Key Feature 3 \& 4: Course Structure \& Alignment

The course site used to be a content repository, like a collection of content such as reading materials, lecture notes, and assignments. In a weekly-based framework, learning modules are setup with topic-level learning objectives that are aligned with measurable learning outcomes. In order to setup measurable learning objectives and make them aligned with desired learning outcomes, it is necessary to adapt instructional design strategies which require knowledge and understanding of instructional design principles.

\section{Key Feature 5: Content Format}

Engineers are visual learners. ${ }^{2}$ The text-heavy content does not appeal to engineering students. One of the significant transformations was converting as much text-based content to visual aids as possible. The old lecture notes were converted to narrative presentation recordings. Most of pdf materials were converted to an online text so that students can view the text-based content directly from an online display such as web pages. Appropriate web resources and graphical content were implemented as well.

Key Feature 6: Practice

It is very common in engineering that students are penalized while they are trying to learn something. A graded homework is one of the examples that students are evaluated while 
practicing. In order to create a safe and fair learning environment, students should have ample opportunities to practice what they are trying to learn. The automated learning process enables students to be prepared for a graded test. Each learning module is setup in a meaningful sequence starting with a reading quiz. When students achieve $100 \%$ success in a reading quiz, an assignment is released. And when students achieve $100 \%$ on an assignment, the access to a weekly test is released. Both a reading quiz and an assignment provide prompt feedback and allow unlimited attempts so that students can try out as many times as they need until they accomplish the desired level of mastery learning.

Key Feature 7: Assessment

A weekly test is timed and available during a certain period so the students are encouraged to work on the practice through a reading quiz and an assignment in a timely manner. Online tests are setup to be auto-graded and individualized with randomly selected set of questions from three difficulty levels (easy/intermediate/difficult) of question pools.

\section{Key Feature 8 \& 9: Monitoring \& Help Session}

Students' progress is monitored by regularly scheduled checkups and notifications through Early Warning System available in Blackboard ${ }^{\mathrm{TM}}$. Based on the rules defined such as a grade of a reading quiz/assignment, the current progress can be observed and the instructor can send out an individual notification. Virtual office is setup and weekly sessions are opened based on questions posted in the virtual office question forum. The weekly Q\&A discussion forums take care of needs for assistance asynchronously as the instructor monitors and responds regularly (i.e. at least once a day)

Key Feature 10: Orientation

Students are encouraged to start from orientation activities available through "Welcome! Start here" appeared on the homepage. It contains an instructor's greetings video clip and introduction to the course, a course walk-through video clip (instructor's video recording demonstrating how to work on the course), a link to an introductory activity (introduce yourself), and a link to a syllabus which contains a syllabus quiz. The syllabus quiz covers important points that students should be informed before starting the course. With unlimited attempts, the completion of a syllabus quiz with $100 \%$ success releases the first learning module.

\section{Course Evaluation}

The renovated course was offered first time during the fall 2011 and students were asked to participate in the study that reflects on their experience of the online course delivery. An 
anonymous survey was disseminated and the participants got extra credits for their submission. The number of total responses were 101 consisting of $82.178 \%$ of males, $15.842 \%$ of females, and $1.98 \%$ of those who preferred not to answer. The majority was in the senior year $(50.495 \%)$ and the rest was fairly distributed to sophomores $(24.752 \%)$ and juniors $(23.762 \%)$. The majority graded their computer literacy to be either good (41.584\%) or excellent $(56.436 \%)$ as well as Internet literacy to be either good (33.663\%) or excellent $(63.366 \%) .56 \%$ of students took an online course for the first time.

The survey was designed with open-ended questions intentionally to receive comprehensive feedback. The participants were encouraged to freely express their opinions based on guided questions (see Appendix A).

Overall, students spent 3-9 hours per week (Monday to Sunday) on the course. Most students expressed that they liked the clear/straightforward framework that the course was delivered in a weekly format with the automated learning process. They expressed frustration caused by the way the weekly tests are setup. They recommended more real world examples would be helpful for their learning.

One of the interesting findings was some students complained of lacking human contact even though they were constantly encouraged to request virtual office sessions if they needed one-onone help. It seems the weekly Q\&A forums took care of most of needs for assistance even though it took place asynchronously.

\section{Conclusion}

The online course is currently being offered for the second time in the spring 2012 semester. The same course evaluation survey will be disseminated at the end of the semester and the responses will be considered for future improvement. One of the revisions currently in-progress based on feedback from the fall 2011 semester is changing the setup in a weekly test. However, due to a limitation for modification on a proprietary system like Blackboard ${ }^{\mathrm{TM}}$, the authors have been considering an open-source option such as Sakai for an alternative course management system.

The purpose of this paper is to share the significant improved experience that one of the authors has been through. His experience based on an instructor's perspective may reflect the value of collaborating with an instructional design expert for such a project like an online course transformation as described in this paper. Instructional design in engineering education is relatively new. It would be worth to seek out for help from instructional design expertise. No matter how the mode of course delivery is determined, well-designed quality instruction is a must to be considered first for creating a better learning experience. 


\section{Appendix A: Guided Questions for Course Evaluation Survey}

Q: Describe your time commitment for this course considering the following questions:

- What was the (average) amount of time you spent on this course per week (from Monday to Sunday)?

- Was the time you were spending in the course valuable?

Q: Describe your opinion of the course content considering the following questions:

- Whether or not you were interested in the material, did you learn something in this course?

- Was there anything more you wanted to learn about [main topic of the course] related topics?

- What part of the course did you find most useful/interesting?

- Was the course delivered in a clear and understandable direction?

Q: Describe your experience of help/support considering the following questions:

- How useful was the weekly discussion board for answering questions?

- Have you participated in virtual office? If so, was it useful? If not, why didn't you consider using virtual office hours?

Q: What were the biggest/most frustrating technical problems which you encountered during the course? Any suggestions for ways in which you might become more familiar and comfortable with the technology used for the delivery of this course?

Q: What did you like about the course?

Q: What did you dislike about the course?

Q: Any other comments for improving the course delivery?

\section{References}

1. Bourne, J., Harris, D. \& Mayadas, F. (2005). Online Engineering Education: Learning Anywhere, Anytime. Journal of Engineering Education, 94(1), 131-146.

2. Felder, R. M., Woods, D. R., Stice, J. E., \& Rugarcia, A. (2000). The Future of Engineering Education: II. Teaching Methods That Work. Chem. Engr. Education, 34(1), 26-39.

3. Rugarcia, A., Felder, R. M., Woods, D. R., \& Stice, J. E. (2000). The Future of Engineering Education: I. A Vision for a New Century. Chem. Engr. Education, 34(1), 16-25. 
4. Wang, S. C. (2009). In K. Jusoff, S. S. Mahmoud, \& R. Sivakumar (Eds.) University Instructor Perceptions of the Benefit of Technology Use in E-Learning. International Conference on Computer and Electrical Engineering (pp. 580-585). Los Alamitos, CA: IEEE Computer Society. 